knowledge on the incidence of disease was discussed by several speakers, and the results of investigations on the connexion between faulty diet and disease in the community were quoted in support of the suggestion that disease due to faulty diet is prevalent. Thus, an investigation showed that about 50 per cent of women of the child-bearing age among the working classes in one of our cities were suffering from nutritional anæmia. The addition of milk to the diet of school children was followed by 20 per cent increase in rate of growth and by improvement in health. A large proportion of children are evidently not attaining their full inherited capacity for health. It was suggested that much of the disease in later life may be due to malnutrition in childhood and that this may have a bearing on the large number of rejections of recruits from the army, owing to poor physique or chronic disease.

If, indeed, disease due to faulty dietary should eventually prove to be as prevalent as these isolated and limited observations suggest, then there are obvious economic and political implications, especially at the present time, when we are moving towards a planned economic system under which the amount of certain foodstuffs coming on the market and the price at which they may be retailed, may be fixed for purely economic reasons. As a matter of fact, we have not sufficient data to warrant making an authoritative statement on the subject. Experimental observations have been far too limited in extent and too academic in nature to permit of wide generalisation. Sir Frederick Gowland Hopkins wisely counselled caution in the interpretation of the limited facts available. The urgent need of the present time is large-scale investigations over a number of years in different sections of the community in order to obtain data which may be applicable to the populace as a whole.

\title{
Pit-Head Generation of Electric Power
}

\section{(From a CoRrespondent)}

TN $\mathrm{N}$ his presidential address before the Engineering Section at the recent British Association meeting at Aberdeen on "Sources of Cheap Electric Power", Prof. F. G. Baily advocates the establishment of electric generating stations at the pitheads, his contention being that with low-grade coal and 'waste' fuel having a calorific value of 10,000 B.Th.U. per lb. available at a cost of five shillings per ton, electricity could be produced at one-twentieth of a penny per unit below the cost of production at the most modern steam stations now operating.

Prof. Baily very properly refers to the heavy burden of local rates on electricity undertakings, amounting in some cases to $0 \cdot 1 d$. per unit sold, and suggests that a substantial reduction may be claimed such as a half, amounting to $0.05 d$. per unit which, with the equal saving which the pithead station with cheap fuel can achieve, will bring about a reduction of $0 \cdot 1 d$. per unit. The present cost of generation at large stations he puts at $0 \cdot 25 d$. In this figure, $0 \cdot 25 d$. per unit generated, rates (on the generating station alone), as Prof. Baily says, may amount to $0.06 d$. per unit, and on the whole undertaking often as much as $0 \cdot 1 d$. per unit sold. This is a serious addition to the price which users of electricity have to pay. At least one undertaking selling many millions of units every year pays more in rates than it does for the coal required to generate all the electricity it sells. With the generating stations of industrial concerns de-rated, a substantial reduction in the rating of public utility stations appears to be a reasonable demand, but any reduction obtained would apply equally to the existing stations and to the proposed pit-head stations and would not affect a comparison between the two.

Prof. Baily visualises a pit-head station (perhaps many stations) having a daily output of about one million units. A saving of one-twentieth of a penny per unit would therefore be well worth striving for, and if such a saving could be effected it seems strange that nothing is being done to connect one such station to the Grid. It is only fair to say that such proposals are not new. In 1919 the Nitrogen Products Committee, with some of the most eminent engineers and other wellknown scientific men of the day among its members, referring to the subject, said :

"It has often been advocated that large power stations should be situated at the collieries or even at the pit's mouth in order that the cost of coal delivered into the bunkers may be reduced to the lowest possible point. This would be perfectly sound provided the other principal requirement of a cheaply operated power station could be obtained at the same site, namely, an abundant natural supply of circulating water for condensing purposes, capable of being utilised without undue cost of pumping. In the case, for example, of a station loaded to $100,000 \mathrm{k} . w$. at least six million gallons of condensing water would be required per hour on a load factor of $95 \%$-some $136,000,000$ gallons per day. The only alternative to a large supply of cooling water is to use cooling towers with a consequent large permanent loss of water by evaporation and a considerable increase in the temperature of the condensing water leading to a serious addition to the 
coal consumption of the Power Station. The constant loss by evaporation into the atmosphere amounts in practice to about $2 \%$ of the total, and as this is irrecoverable it has to be constantly made up from an outside source. In the case cited above of a $100,000 \mathrm{k} . \mathrm{w}$. station operating on a load factor of $\mathbf{9 5 \%}$ the employment of cooling towers would necessitate a daily supply of $2 \cdot 72$ million gallons of make up water to replace losses. ... To sum up, the large power station at a colliery site having to rely upon cold water for condensing purposes involves an increased capital expenditure, an increased consumption of coal, a large initial supply of water for the towers and a large daily supply for make up purposes. . . The Committee is not aware of any localities in Great Britain where natural supplies of condensing water of the magnitude indicated above can be obtained at the pit's mouth or in proximity to collieries and it is impracticable to transmit so large an amount of water over any considerable length of pipe. ..."

In 1925 the matter was considered by the Coal Commission, which took evidence as to the practicability of having large generating stations located at the collieries. Then in 1926 the Board of Trade appointed the National Fuel and Power Committee to consider and advise upon questions connected with the economical use of fuels and their conversion into various forms of energy. This Committee made the following observation :

"The generation of electricity at the pit head is at first so very attractive that it is frequently advocated; but consideration of all the relevant factors makes it evident that the cheapness of low grade fuel in a colliery district does not necessarily make it desirable that electricity for general public supply should be generated there. The determination of sites for future capital stations is in the hands of the Central Electricity Board, and the Electricity Commissioners and the Central Electricity Board will naturally take its supplies from the most economical stations. Where circumstances favour the erection of a station of large capacity in a colliery district there is no doubt that the saving in the transport of coal will give such a station added advantage. But the choice of a site for a generating station to supply a central network depends on a balance of considerations. The larger the capacity of the station, other things being equal, the lower is the cost of generation. The cost of transmission and distribution are also of importance and a station in the centre of a body of large consumers has an advantage in this respect. . . . It appears to us therefore that the question whether the Power Station should be at the pit or away from it or whether the colliery power station should be larger than is required to supply the colliery's own requirements or indeed whether the colliery power station is in any given case necessary at all, or whether the energy should not be taken from the national system must be decided on the merits of each particular case, having regard to local and district conditions. ... We recommend that the possibility of the use of low grade fuel should be carefully considered when the site of any new electricity generating station is under consideration and when the plant for the station is designed and that the desirability of making any necessary adaptations of plant for the use of such fuel should be considered even for the existing stations. . .."

It is fifteen years since the Nitrogen Products Committee issued its report, and Prof. Baily's answer to the criticism contained in it in regard to cooling towers, is that with the higher steam pressures now in use the reduction in efficiency due to the lower vacuum obtained with cooling towers is often exaggerated, and he mentioned the Hams Hall Station at Birmingham with a fuel consumption of $1.35 \mathrm{lb}$. per unit and an overall thermal efficiency of $23 \cdot 34$ per cent, in support of his contention. The Battersea Station on the Thames, Clarence Dock Station on the Mersey, and the Ironbridge Station on the Severn, may be mentioned as typical examples of coal-burning stations located at suitable centres. All three have a thermal efficiency exceeding 26 per cent, and no doubt this will be improved upon by the time any pit-head station is connected to the Grid.

The magnitude of the water problem may be judged by the fact that about 500 tons of water is circulated for every ton of coal burned, and last year more than $10 \frac{1}{2}$ million tons of coal were consumed at the stations of electricity supply authorities. There has been an improvement in recent years in the efficiency of cooling towers, but that improvement is scarcely sufficient to justify Prof. Baily's claim that "the absence of cooling water can be definitely disregarded as a disability in the use of pit-head stations".

The lower operating efficiency with cooling towers and higher capital cost, amounting to $£ 100,000$ in Prof. Baily's 100,000 k.w. station, are items which are not likely to be disregarded by those engineers who are responsible for the building of new stations or the extension of existing ones.

The suggested saving of one-twentieth of a penny per unit generated at the pit-head will suffer a further reduction when the cost of lines to connect it with the Grid are added. Prof. Baily suggests that transmission cost will be small, but sub-station equipment and duplicate lines would be necessary, and the cost in some cases considerable. The above-mentioned additional costs can, of course, be arrived at within close limits, but how is the price of 'waste' fuel having a calorific value of 10,000 B.Th.U. per lb. to be stabilised at 5s. a ton? With generating stations built for the purpose of utilising this low-grade coal, it might become a main product, and with an increased demand the price would surely rise unless some agreement were made to keep it sufficiently low to enable the pit-head station to compete successfully with existing stations. In theory it is an attractive plan to use low-grade 
fuel, cut out certain waste at the collieries and generally improve their efficiency, but the merits of such a scheme must rest on economic facts.

Prof. Baily bases his main comparison on stations working on a load factor of 40 per cent, but in future there will be two types of station in operation, the base load station working on a load factor of something of the order of 80 per cent and peak load stations operating on a poor load factor. Into which category are the pit-head stations to be put?

We think there may be individual cases where a pit-head station will compare favourably with an existing selected station, but we can see no substantial evidence to justify any general scheme which would reduce the number or render redundant the existing base load stations. As soon as it can be proved that the pit-head generating station is capable of supplying energy to the Grid at a price below that of the most modern stations now connected to it we believe that: (1) capital will be found for such a station; (2) the Central Electricity Board will be prepared to enter into a contract to purchase the whole of the station output; and (3) the Electricity Commissioners will give their consent.

\section{International Conference on Physics}

COME time ago, the Physical Society became $D$ convinced that results of value could be anticipated from an international conference on atomic (particularly nuclear) physics, and it was the intention of the Society to call such a conference this year. At the same time, the British National Committee for Physics-one of the constituent bodies which together form the International Union of Pure and Applied Physicsproposed to invite the Union to hold its next meeting in Great Britain.

It was a natural step to amalgamate these two functions, and the six-day meeting on October 1-6 has amply demonstrated the wisdom of that step. It was, we believe, the first occasion on which a meeting of the International Union had taken the form of a colloquium, and it brought together a most impressive array of physicists of note from many countries. The actual membership was nearly 600 , of whom some 150 came from abroad. The international nature of the conference was perhaps best illustrated when an Italian, speaking in French, gave to the mainly English audience an account of recent work by a German who was unable to attend in person. The meeting was held in London in the rooms of the Royal Society and at the Royal Institution, and in addition, at the invitation of Lord Rutherford, one session was held at the Cavendish Laboratory, Cambridge.

The more formal business of the International Union included the ratification of a report on symbols and definitions, with which we hope to deal later, and the election of Prof. Niels Bohr to succeed Prof. R. A. Millikan in the presidential chair. In addition to this, the Union was responsible for the organisation of a discussion on certain problems of the solid state. In crystals, there is much evidence tending to show that, over and above the lattice regularity revealed by $\mathrm{X}$-rays, there is a further definite structure, on a larger scale. The existence of such a block or mosaic structure was much debated, but assuming it to exist, it becomes a question of great interest to decide whether it is present inevitably, as a consequence of the need for the potential energy to become a minimum, or whether it is fortuitous, and due to something in the nature of flaws distributed statistically. The theoretical question involved here was discussed in one form or another at several of the meetings, and it seems likely that a solution will at least be expedited by the interplay of ideas and by consideration of the numerous suggestions made.

The most immediately obvious point about crystals is their lack of tensile strength, as compared with the value to be expected on theoretical grounds. The difference for rock-salt, for example, is about a thousand-fold, and two rival theories are in existence to account for this. One theory is that outlined above; the other locates the weaknesses at cracks on the surface of the specimen. This crack theory receives strong support from many experiments where surface treatment alone has been found to alter the tensile strength considerably ; perhaps the most striking illustration is the discovery by Joffé and others, that the strength of rock-salt is increased twentyfive fold by merely carrying out the experiments in hot water. Of course, it must be borne in mind that a block structure might still exist, even if not needed to explain this particular fact. Much of the evidence for a block structure rests on data obtained by studies of plastic yielding, as well as on chemical facts and microscopic examination.

That part of the conference for which the Physical Society was directly responsible concerned itself with certain aspects, mainly experimental, of the recent advances in nuclear physics. It is true that fifteen years have elapsed since Lord Rutherford first succeeded in demonstrating that certain nuclei could be disintegrated by 